of onset of cases derived from questionnaire data, however, there was no consistent seasonal pattern for cases in which contact with farm animals had or had not been reported. A clear seasonal pattern, however, would not be expected, given the observation that most laboratories experienced infrequent and irregular sudden community wide increases in cryptosporidiosis. Such outbreaks are hard to explain by faecal-oral spread, and the possibility of common source infection must be considered. Outbreaks due to waterborne infection have been confirmed, ${ }^{18-21}$ and this possibility is of growing concern in the United Kingdom.

Once introduced into a human population, cryptosporidium can spread readily by the faecal-oral route, especially in nurseries. Our data showed that up to a quarter of cases were followed by other cases of gastroenteritis in household members, which could have been due to secondary spread, although, unfortunately, faecal samples were often not submitted in these cases to confirm the nature of the infection. Transmission in households after infection of index cases from direct farm animal contact has been described. ${ }^{22}$ Surveillance to identify community clusters and prompt investigation should be undertaken to identify sources of infection and possible preventive measures.

We thank all our medical laboratory scientific officers and microbiologist colleagues in the Public Health Laboratory Service who carried out the routine laboratory work, and environmental health officers and general practitioners who helped in gathering information on patients.

1 Nime FA, Burek JD, Page DL, Holscher MA, Yardley JH. Acute enterocolitis in a human being infected with the protozoan Cryptosporidium. Gastroen1976:70:592-8.

2 Navin TR, Juranek DD. Cryptosporidiosis: clinical, epidemiologic and parasitologic review. Rev Infect Dis 1984;6:313-27.

3 Anonymous. Cryptosporidiosis: assessment of chemotherapy of males with acquired immunodeficiency syndrome (AIDS). MMWR 1982;31:589-92.

4 Jokipii L, Pohjola S, Jokippii AMM. Cryptosporidium: a frequent finding in patients with gastrointestinal symptoms. Lancet 1983;ii:358-61.

5 Casemore DP. Cryptosporidiosis. PHLS Microbiology Digest 1987; 4: 1-5.

6 Hunt DA, Shannon R, Palmer SR, Jephcott AE. Cryptosporidiosis in an urban community. Br Med f 1984:289:814-6.

Baxby D, Hart CA. The incidence of cryptosporidiosis: a two year prospective survey in a children's hospital. foumal of Hygiene 1986:96:107-11.

8 Casemore DP, Armstrong M, Jackson FB. Screening for cryptosporidium in stools Lancet $1984 ;$; 7345 .

9 Nichols G, Thom BT. Screening for cryptosporidium in stools. Lancel 1984; : 735 .

10 Skirrow MB. A demographic survey of campylobacter, salmonella and shigell infections in England. Epidemiol Infect 1987;99:647-57.

11 Bannister P, Mountford RA. Crytosporidium in the elderly: a cause of lifethreatening diarrhoea. Am $\mathcal{F}$. Med 1989;86:507-8.

12 Casemore DP, Armstrong M, Sands RL. Laboratory diagnosis for cryptosporidiosis. F Clin Pathol 1985;38:1337-41.

13 McLauchlin J, Casemore DP, Harrison TG, et al. Identification of cryptosporidium oocysts by monoclonal antibody. Lancet 1987;i:51.

14 Casemore DP, Jessop EG, Douse D, Jackson FB. Cryptosporidium plus campylobacter: an outbreak in a semirural population. Fournal of Hygien 1986;96:95-105.

15 Current WL, Reese NC, Ernst JV, Bailey WS, Heyman MB, Weinstein WM. Human cryptosporidiosis in immunocompetent and immunodeficient persons. Nezu Engl f Med 1983.308:1252-7.

16 Thomson MA, Benson JWT, Wright PA. Two year study of cryptosporidium infection. Arch Dis Child 1987;62:559-63.

17 Casemore DP. Cryptosporidiosis: another source. Br Med f 1989;298:750-1.

18 Isaac-Renton JL, Foged D, Stibbs HH, Ongerth JE. Giardia and cryptosporidium in drinking water. Lancet 1987; i:973-4.

19 D'Antonio RG, Winn RE, Taylor JP, et al. A waterborne outbreak of cryptosporidiosis in normal hosts. Ann Intern Med 1985;103:886-8.

20 Hayes EB, Malte TD, O'Brian TR, et al. Large community outbreak of cryptosporidiosis due to contamination of a filtered public water supply. New Engl f Med 1989;320:1372-6.

21 Smith HV, Girdwood RWA, Patterson WJ, et al. Waterborne outbreak of cryptosporidiosis. Lancet 1988;ii:1484.

22 Ribeiro CD, Palmer SR. Family outbreak of cryptosporidiosis. Br Med $\mathcal{f}$ 1986;292:377

(Accepted 19 December 1989)
Departments of Cardiology and Radiology, Newham General Hospital, London E13 8SL

K Ranjadayalan, MRCP, research registrar

K Mourad, FRCR, consultant radiologist

Department of Cardiology, The London Hospital, London E1 1BB

P G Mills, FRCP, consultant cardiologist

Departments of Cardiolog and Cardiothoracic Surgery, The London Chest Hospital, London E2 9JX

D C Sprigings, MRCP, cardiology registrar

P Magee, FRCS, consultant cardiothoracic surgeon

A D Timmis, MD, consultant cardiologist

Correspondence to:

Dr Timmis, department of cardiology.

BrMed f 1990;300:777-80

\title{
Coronary arteriography in a district general hospital: feasibility, safety, and diagnostic accuracy
}

\author{
K Ranjadayalan, P G Mills, D C Sprigings, K Mourad, P Magee, A D Timmis
}

\section{Abstract}

Objective-To determine the feasibility, safety, and diagnostic accuracy of coronary arteriography in the radiology department of a district general hospital using conventional fluoroscopy and videotape recording.

Design-Observational study of the feasibility and safety of coronary arteriography in a district general hospital and analysis of its diagnostic accuracy by prospective within patient comparison of the video recordings with cinearteriograms obtained in a catheter laboratory.

Setting-Radiology department of a district general hospital and the catheter laboratory of a cardiological referral centre.

Subjects-50 Patients with acute myocardial infarction treated with streptokinase who underwent coronary arteriography in a district general hospital three (two to five) days after admission. 45 Of these patients had repeat coronary arteriography after four (three to seven) days in the catheter laboratory of a cardiological referral centre.

Main outcome measures-Incidence of complications associated with catheterisation and the sensitivity and specificity of video recordings in the district general hospital (judged by two experienced observers) for identifying the location and severity of coronary stenoses.

Results-Coronary arteriograms recorded on videotape in the district general hospital were obtained in 47 cases and apart from one episode of ventricular fibrillation (treated successfully by cardioversion) there were no complications of the procedure. 45 Patients were transferred for investigation in the catheter laboratory, providing 45 paired coronary arteriograms recorded on videotape and cine film. The specificity of the video recordings for identifying the location and severity of coronary stenoses was over $\mathbf{9 0 \%}$. Sensitivity, however, was lower and for one observer fell below $\mathbf{4 0} \%$ for lesions in the circumflex artery. A cardiothoracic surgeon judged that only nine of the 47 video recordings were adequate for assessing revascularisation requirements.

Conclusions-Coronary arteriography in the radiology department of a district general hospital is safe and feasible. Nevertheless, the quality of image with conventional fluoroscopy and video film is inadequate and will need to be improved before coronary arteriography in this setting can be recommended.

\section{Introduction}

Vascular imaging is performed routinely in the radiology departments of many district general hospitals. Coronary arteriography, however, is restricted to specialist centres equipped with a catheterisation laboratory. Waiting lists are often long and patients with suspected coronary artery disease may have to 
wait several months for investigation. The pressure on catheterisation laboratories has increased with the advent of coronary angioplasty and other interventional procedures which can be performed only with cardiothoracic surgical back up. Meanwhile, there are increasing numbers of district general hospital cardiologists who, though fully trained in catheterisation, must continue to refer patients elsewhere for coronary arteriography. The case for establishing a coronary arteriography service within the district general hospital is therefore attractive and merits investigation.

\section{Subjects and methods}

We studied 50 patients (table I). All gave informed written consent, and the study was approved by the Newham Health District ethical committee. Patients were recruited from a consecutive series of 68 patients with acute myocardial infarction admitted to the coronary care unit and treated with intravenous steptokinase $\left(1.5 \times 10^{6} \mathrm{IU}\right.$ infused over one hour $)$. Thereafter the patients received heparin either by intravenous infusion $(1000 \mathrm{IU} / \mathrm{h})$ or subcutaneously $(5000 \mathrm{IU}$ three times a day) until coronary arteriography had been performed in the catheter laboratory. Of the 18 patients excluded from the study, three died early after admission, two were considered medically unfit for cardiac catheterisation, three required early discontinuation of streptokinase because of hypotensive reactions, three refused to give consent, and seven could not be included for logistical reasons.

Coronary arteriography - was performed in the hospital radiology department by a modified Judkins technique three (two to five) days after admission. Size 5 French gauge Super-Flow catheters (Cordis) and low viscosity contrast solution were used to minimise bleeding from the arterial puncture site and ensure adequate delivery of contrast (table II). The catheters were introduced through a short 5 French gauge sheath placed in the right femoral artery. The electrocardiogram was monitored throughout each procedure. A Philips BV 25 fluoroscopy system equipped with a

TABLE I - Details of patients recruited to study

\begin{tabular}{|c|c|}
\hline & $\begin{array}{l}\text { No of patients/median } \\
\text { value }\end{array}$ \\
\hline \multicolumn{2}{|l|}{ Sex distribution: } \\
\hline Men & 42 \\
\hline Women & 8 \\
\hline Age (years) (range) & $62(53-68)$ \\
\hline \multicolumn{2}{|l|}{ Location of infarct: } \\
\hline Anterior & 28 \\
\hline Inferior & 22 \\
\hline $\begin{array}{l}\text { Time streptokinase infusion begun after onset of } \\
\text { pain (hours) (range): }\end{array}$ & $3 \cdot 5(2 \cdot 8-5 \cdot 3)$ \\
\hline \multicolumn{2}{|l|}{$\begin{array}{l}\text { Serum creatine kinase activity (IU/l) } \\
\text { (interquartile range): }\end{array}$} \\
\hline Day of admission (day 0$)$ & $138(91-233)[n=44]$ \\
\hline Day 1 after admission & $1339(748-2466)[n=47]$ \\
\hline Day 2 after admission & $385(256-962)[n=34]$ \\
\hline \multicolumn{2}{|l|}{$\begin{array}{l}\text { Time cardiac catheterisation performed after } \\
\text { admission (days) (interquartile range): }\end{array}$} \\
\hline District general hospital & $3(2-5)[n=50]$ \\
\hline Catheter laboratory & $4(3-7)[n=45]$ \\
\hline
\end{tabular}

TABLE II - Catheterisation equipment

\begin{tabular}{lcc}
\hline & $\begin{array}{c}\text { District general } \\
\text { hospital }\end{array}$ & $\begin{array}{c}\text { Catheterisation } \\
\text { laboratory }\end{array}$ \\
\hline $\begin{array}{l}\text { Contrast solution: } \\
\text { Identity }\end{array}$ & $\begin{array}{c}\text { Iopamidol }[\mathrm{n}=40], \\
\text { iopromide }[\mathrm{n}=10] \\
8 \cdot 0-8 \cdot 8\end{array}$ & $\begin{array}{c}\text { Meglumine/sodium } \\
\text { diatrizoate }[\mathrm{n}=45] \\
16 \cdot 5\end{array}$ \\
$\begin{array}{l}\text { Viscosity (mPa.s) } \\
\text { Judkins catheter: }\end{array}$ & 5 (Super-Flow) \\
Size (French gauge) & $1 \cdot 1$ & 7 \\
Internal diameter $(\mathrm{mm})$ & $8 \cdot 3$ & $1 \cdot 2$ \\
Flow rate $(\mathrm{ml} / \mathrm{s}) \dagger$ & & $7 \cdot 9$ \\
\hline
\end{tabular}

^Viscosity measured at $20^{\circ} \mathrm{C}$.

+Flow rates, adjusted for contrast viscosity, are for pressure of $21.0 \mathrm{~kg} / \mathrm{cm}$ (approximating that achieved by hand injection with $10 \mathrm{ml}$ syringe).

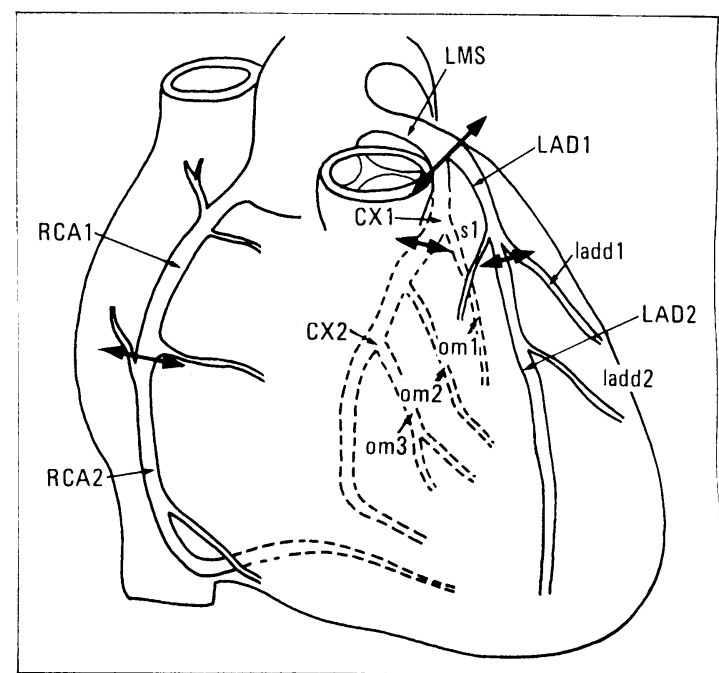

Coronary arterial map for locating coronary stenoses and occlusions. Broken lines indicate posteriorly located arteries. Left anterior descend ing $(L A D)$, circumflex $(C X)$, and right coronary $(R C A)$ arteries are divided into proximal (1) and distal (2) segments as indicated by arrowed lines. Left main stem (LMS), diagonal (ladd), and obtuse marginal (om) branches are given separate designations. ( $s l=$ First septal branch of left anterior descending artery.

rotating $\mathrm{C}$ arm was used for imaging. Arteriography was performed with $5-8 \mathrm{ml}$ hand injected iopamidol (Niopam 300) in the first 40 patients and iopromide (Ultravist 300) in the remainder. Images in multiple views (left three (two to four), right two (two or three)) were recorded on videotape. The patients were then transferred for arteriography in the catheter laboratory four (three to seven) days after admission. The arterial sheath was not removed unless transfer was delayed beyond three days, and in most cases the same arterial puncture site was used for the second catheter procedure after a larger sheath had been substituted to accommodate 7 French gauge coronary catheters. A Siemens imaging system was used and multiple views of both coronary arteries (left five (all cases), right three (two or three) obtained by $5-8 \mathrm{ml}$ hand injections of a proprietary combination of meglumine diatrizoate and sodium diatrizoate (Urografin 370 ). The images were recorded on cine film.

Analysis of arteriograms-Paired coronary arteriograms (recorded on videotape and cine film) from 45 patients were available for analysis. Each of the 90 arteriograms was reported on independently by two cardiologists to assess the diagnostic accuracy of the video recordings. In reporting the arteriograms the cardiologists were required to report only the locations of coronary stenoses and occlusions and whether they were clincally "significant" $(\geqslant 70 \%)$. The locations of the lesions were identified according to a simple arterial map (figure). Thus the left anterior descending, circumflex, and right coronary arteries were divided into proximal and distal segments with separate designations for the left main stem, diagonal, and lateral circumflex branches. The video recordings were also reviewed by a cardiothoracic surgeon to determine their suitability for surgical decision making.

Statistical analysis-All averaged values are expressed as median with the interquartile range in parentheses. Sensitivity was defined as true positive divided by true positive plus false negative results, and specificity as true negative divided by true negative plus false positive results.

\section{Results}

Coronary arteriography in the district general hospital was successful in 47 of the 50 cases with an average screening time of $4.9(3 \cdot 2-5 \cdot 8)$ minutes. In three patients coronary arteriograms could not be obtained. 
Two had bilateral iliofemoral disease preventing access to the coronary circulation and one developed excessive bleeding at the femoral puncture site. Five other patients developed haematomas at the femoral puncture site but in no case was bleeding severe enough to require blood transfusion. There were no other complications apart from ventricular fibrillation in one patient (treated successfully by cardioversion).

Coronary arteriography in the catheter laboratory-Of the 47 patients on whom coronary arteriograms were recorded on videotape, one refused further participation. One other patient with a recanalised dominant circumflex artery suffered reinfarction in the same territory two hours after an uncomplicated catheter procedure and later died. The remaining 45 patients were transferred for investigation in the catheter laboratory, which was successful in every case with an average screening time of $3 \cdot 0(3 \cdot 0-4 \cdot 0)$ minutes. There were no complications related to the procedure apart from minor bleeding around the femoral puncture site in nine patients, none of whom required blood transfusion.

\section{ANALYSIS OF ARTERIOGRAMS}

Diagnostic accuracy of videoarteriograms compared with cinearteriograms (table III)-The sensitivity and specificity of the video recordings for identifying patency of the infarct related coronary artery were $97 \%$ and $69 \%$ repectively. For determining the location and severity of the lesions in each of the three major coronary arteries, however, specificity was in excess of $90 \%$ for both observers, although sensitivity was lower and fell below $40 \%$ in the circumflex system. Elsewhere in the coronary vasculature the sensitivity of the video recordings was much higher, such that overall values for location and severity of the lesion were in excess of $75 \%$ and $60 \%$ respectively for both observers.

Surgical decision making - The 47 videoarteriograms were reviewed independently by a cardiothoracic surgeon, who found only nine of them adequate for surgical decision making.

\section{Discussion}

This study shows that coronary arteriography is feasible and safe using conventional fluoroscopy facilities in the radiology department of a district general hospital. Paired coronary arteriograms from individual patients, however, confirmed that the quality of image of the video recordings in the district general hospital was inferior to the cine recordings obtained in the catheterisation laboratory of a cardiological centre and in most patients was inadequate for surgical decision making. Thus the main constraint on coronary arteriography in district general hospitals is related less to the practicality of the procedure than to the technology of acquiring and storing the image. Until these problems are resolved coronary arteriography by using the conventional facilities of the district general hospital radiology department cannot be recommended.

Previous investigators have reported the feasibility and safety of coronary arteriography during acute myocardial infarction using conventional fluoroscopy in the coronary care unit. ${ }^{12}$ These studies were aimed at determining patency of the infarct related coronary artery after thrombolytic treatment, and for this limited purpose the quality of image was reported as satisfactory. Hillis et al suggested that the low capital and running costs of the procedure might make its widespread application possible within the setting of a district general hospital. In this study we also selected patients with acute myocardial infarction who had received thrombolytic treatment as it was our policy to refer all such patients for coronary arteriography. Our findings confirm that coronary arteriography can be performed quickly and safely in the radiology department of a district general hospital with a total imaging time only slightly longer than that required in the catheterisation laboratory and without excessive complications.

Our series was fairly small, however, and a more complete assessment of the safety of the procedure would require larger numbers. Indeed, it has recently been argued that diagnostic coronary arteriography, like coronary angioplasty, should be performed only in centres with immediate access to cardiac surgery. ${ }^{3}$ Nevertheless, this view is not widely held as evidenced by the number of centres in Britain and elsewhere where diagnostic coronary arteriography is performed routinely and safely without surgical back up. Moreover, the $0 \cdot 1-0 \cdot 2 \%$ mortality for coronary arteriography $y^{+6}$ is almost certainly lower than the mortality among patients on the waiting list in Britain, although there are no published data on this contentious issue. This consideration should not be overlooked in assessing the merits of a catheterisation programme in district general hospitals, which would have the useful effect of shortening waiting lists, possibly reducing overall mortality.

An important part of our study included assessing the quality of image and diagnostic accuracy of the district general hospital video recordings by comparing them with paired cinearteriograms obtained in a cardiac catheterisation laboratory. All arteriograms were reported by two experienced observers. Although the specificity of the video recordings was uniformly high for both observers, the sensitivity was appreciably lower. This was particularly so for lesions in the circumflex system, where values for severity fell as low as $32 \%$. Such a level of sensitivity is quite inadequate for reaching a diagnosis, and in the opinion of a cardiothoracic surgeon only nine of the 47 video recordings reviewed were satisfactory for planning revascularisation.

The inferior quality of image of the video recordings was unrelated to differences in catheterisation technique between the two centres. Although smaller catheters were used in the district general hospital, their flow characteristics and the use of low viscosity contrast ensured that delivery of contrast was comparable to that achieved in the catheterisation laboratory. Indeed, other investigators have confirmed that coronary arteriography with use of 5 French gauge catheters provides diagnostic images in over $97 \%$ of

TABLE III - Diagnostic accuracy of videoarteriograms in district general hospital compared with cinearteriograms in catheter laboratory

\begin{tabular}{|c|c|c|c|c|c|c|c|c|}
\hline & \multicolumn{4}{|c|}{ Sensitivity $(\%)$} & \multicolumn{4}{|c|}{ Specificity $(\%)$} \\
\hline & \multicolumn{2}{|c|}{ Observer 1} & \multicolumn{2}{|c|}{ Observer 2} & \multicolumn{2}{|c|}{ Observer 1} & \multicolumn{2}{|c|}{ Observer 2} \\
\hline & $\begin{array}{c}\text { Location } \\
\text { of } \\
\text { lesion }\end{array}$ & $\begin{array}{c}\text { Severity } \\
\text { of } \\
\text { lesion }\end{array}$ & $\begin{array}{c}\text { Location } \\
\text { of } \\
\text { lesion }\end{array}$ & $\begin{array}{l}\text { Severity } \\
\text { of } \\
\text { lesion }\end{array}$ & $\begin{array}{c}\text { Location } \\
\text { of } \\
\text { lesion }\end{array}$ & $\begin{array}{c}\text { Severity } \\
\text { of } \\
\text { lesion }\end{array}$ & $\begin{array}{c}\text { Location } \\
\text { of } \\
\text { lesion }\end{array}$ & $\begin{array}{c}\text { Severity } \\
\text { of } \\
\text { lesion }\end{array}$ \\
\hline Right coronary artery & 87 & 86 & 93 & 77 & 93 & 90 & 93 & 93 \\
\hline Circumflex and lateral branches & 75 & 65 & 39 & 32 & 94 & 94 & 95 & 94 \\
\hline Left anterior descending coronary artery and diagonal branches & 85 & 85 & 85 & 66 & 93 & 92 & 93 & 90 \\
\hline Total (all coronary arteries) & 83 & 80 & 77 & 61 & 94 & 92 & 94 & 92 \\
\hline
\end{tabular}


cases. Undoubtedly, therefore, the main factor contributing to the inferior quality of coronary arteriograms in the district general hospital was the imaging and recording equipment itself, which was unable to compete with the purpose built system in the catheter laboratory.

Thus quality of image is the main constraint on coronary arteriography using the conventional facilities of a radiology department in a district general hospital. As the new generation of digital imaging equipment becomes available coronary arteriography in district general hospitals may become a more realistic prospect. Digital subtraction techniques not only provide superior quality of image but also permit highly accurate automated quantification of coronary stenoses. ${ }^{89}$ Nevertheless, if this new technology is to extend to the role of district general hospital radiology departments it will need to provide images at least as good as those obtained in the catheterisation laboratories of cardiological centres. In this study conventional fluoroscopy with videotape recording failed that test and cannot therefore be recommended for coronary arteriography in the district general hospital.

1 Hillis WS, Jones CR, Been M, Campbell BC, Fulton WFM. Intracoronary thrombolytic therapy performed within a coronary care unit: one year's experience. Scoll Med f 1986;31:25-9.

2 Timmis AD, Griffin B, Crick JC, Sowton E. Anisoylated plasminogen streptokinase activator complex in acute myocardial infarction: a placebocontrolled arteriographic coronary recanalization study. $\mathcal{J} \mathrm{Am}$ Coll Cardiol 1987;10:205-10.

3 Stewart JT, Ward DE, Pumphrey CW, Redwood D. Cardiac catheterisation as an outpatient procedure. Br Med f 1989;298:1182.

4 Davis K, Kennedy JW, Kemp HG, Judkins MP, Gosselin AJ Killip T. Complications of coronary arteriography from the collaborative study of coronary artery surgery (CASS). Circulation 1979;59:1105-11.

5 Kennedy JW, Baxley WA, Bunnell IL, et al Mortality related to cardiac catheterization and angiography. Cathet Cardiovasc Diagn 1982;8:323-40. catheterization and angiography. Cathet Cardiovasc Diagn 1982;8:323-40.
Kennedy JW. Complications associated with cardiac catheterization and Kennedy JW. Complications associated with cardiac catheterization anc angiography. Cathet Cardiovasc Diagn 1982;8:5-11

7 O'Sullivan JJ, Crean P, Walsh M, et al. Cardiac catheterisation using 5-French catheters. Eur Hearl f 1989;10 (abstr suppl): 17

8 Mancini GBJ, Simon SB, McGillem MJ, LeFree MT, Friedman HZ, Voge RA. Automated quantitative coronary arteriography: morphologic and physiologic validation in vivo of a rapid digital angiographic method. Circulation 1987;75:452-60.

9 Cusma JT, Toggart EJ, Folts JD, et al. Digital subtraction angiographic imaging of coronary flow reserve. Circulation 1987;75:461-72.

Accepted 15 7anuary 1990

\title{
Alcohol intake: a risk factor for psoriasis in young and middle aged men?
}

\author{
Kari Poikolainen, Timo Reunala, Jaakko Karvonen, Jorma Lauharanta, Päivi Kärkkäinen
}

\section{National Public Health} Institute, Mannerheimintie 166, 00300 Helsinki, Finland

Kari Poikolainen, MD, scientist

\section{Department of Dermatology, Tampere University Central Hospital, Ritakatu 1, 33520 Tampere, Finland Timo Reunala, $\mathrm{MD}$, associate professor \\ Department of Dermatology, Oulu University Central Hospital, Kajaanintie 52, 90220 Oulu, Finland Jaakko Karvonen, MD, associate professor}

\section{Department of} Dermatology, Helsinki University Central Hospital, Snellmaninkatu 14, 00170 Helsinki, Finland Jorma Lauharanta, $\mathrm{MD}$, senior dermatologist

Research Unit for Alcohol Diseases, University of Helsinki, Tukholmankatu 8F, 00290 Helsinki, Finland Päivi Kärkkäinen, LICMED, research assistant

Correspondence to: Dr Poikolainen.

\section{Abstract}

Objective - To clarify the nature of the association between alcohol intake and psoriasis.

Design-Case-control study of men aged 19-50 with onset of skin disease in $\mathbf{1 9 7 6}$ or later.

Setting-Outpatient clinics of the departments of dermatology of the university central hospitals in Helsinki, Oulu, and Tampere from September 1987 to April 1989.

Subjects-144 Patients with psoriasis and 285 unmatched controls with other skin diseases.

Main outcome measures-Results of clinical examination and self administered questionnaire assessing lifestyle and alcohol intake during two specified periods-namely, 12 months before the onset of skin disease and 12 months before the date of examination.

Results-Recalled mean alcohol intake before the onset of skin diseases was $42.9 \mathrm{~g} /$ day among the patients with psoriasis and $21.0 \mathrm{~g} /$ day among the controls. In logistic regression analysis psoriasis was associated with alcohol intake but not with coffee consumption, smoking, age, marital state, or social group. The odds ratio for psoriasis at an alcohol intake of $100 \mathrm{~g} /$ day compared with no intake was $2 \cdot 2$ (95\% confidence interval 1.3 to 3.9 ). The controls decreased their alcohol intake after the onset of the disease but the group with psoriasis did not. Analysis of serum enzyme values showed that $\gamma$-glutamyltransferase activity was significantly correlated with alcohol intake $(r=0.35)$, the mean activity being 75.0 U/1 among patients with psoriasis and $41.9 \mathrm{U} / 1$ among controls.

Conclusions - Alcohol is a risk factor for psoriasis in young and middle aged men, and psoriasis may sustain drinking.

\section{Introduction}

The relation between alcohol and psoriasis is controversial. Some studies suggest that psoriasis is more prevalent $^{1.3}$ and more severe ${ }^{45}$ among heavy drinkers whereas other studies have not found any association. ${ }^{6-11}$
The course of psoriasis is chronic. Skin manifestations may be severe and cause emotional problems, ${ }^{12}$ which themselves may lead to relief drinking. Our study aimed at clarifying whether psoriasis increases drinking, whether drinking increases the risk of psoriasis, and whether drinking worsens psoriasis.

\section{Patients and methods}

We studied consecutive male patients with psoriasis and male controls with other skin diseases admitted to the outpatient clinics of the departments of dermatology of the university central hospitals in Helsinki, Oulu, and 'Tampere from September 1987 to April 1989. We ignored whether patients were treated as outpatients or inpatients. To reduce errors in recall and reporting bias $^{13}$ we restricted the study group to patients aged 19-50 whose onset of skin disease was in 1976 or later. We aimed at collecting 50 patients with psoriasis and 100 controls in each centre. Six patients with psoriasis and two controls refused. One patient with psoriasis was too drunk to cooperate and five others gave no specific reason for refusal, and one control patient was too busy and another thought the questions too personal.

Of the 451 patients originally collected, 15 failed to meet the study criteria and six did not answer the question concerning the onset of their skin disease. Of the 15 patients who failed to meet the study criteria, eight were younger than 19 , two were over 50 , and five had had their skin disease since before 1976. One patient with psoriasis was excluded because his admitted alcohol intake of $28 \mathrm{~g}$ /day was incompatible with the clinical signs of intoxication and extremely high laboratory values (for example, $\gamma$-glutamyltransferase activity $1160 \mathrm{U} / \mathrm{l}$, mean corpuscular volume $104 \mathrm{fl}$ ). The final study group thus comprised 144 patients with psoriasis and 285 controls (table I).

\section{CHARACTERISTICS OF THE PATIENTS}

No significant differences were found between the patients with psoriasis and the controls with respect to age, marital state, and social class distribution. The 